\title{
Mimesis y representación: algunos apuntes sobre la razón mimética
}

\section{Mimesis and representation: some notes on mimetic reason}

\author{
Rodrigo García de la Sienra \\ Universidad Veracruzana, México \\ ORCID: 0000-0002-5204-1731 \\ rgarciadelasiernra@uv.mx
}

\section{RESUMEN}

Este artículo aborda el problema de la mimesis desde una perspectiva arqueológica; y tiene como hilo conductor la transformación que sufrieron en Grecia las categorías arcaicas, relativas a la percepción de lo invisible o de la presencia ausente, ello a raíz del advenimiento de las instituciones de la polis, así como de las tecnologías de la representación, que estuvieron asociadas con la emergencia de su novedoso marco de publicidad. Desde ese umbral, se busca situar la idea de una razón mimética, cuya relación con la verdad se fundamenta en una forma de conciencia hecha posible por el trabajo con los poderes del imaginario y de la representación.

Palabras clave: mimesis; representación; eidolon; eikon; imagen; razón mimética.

\section{ABSTRACT}

This article is about mimesis from an archaeologic perspective; and follows the thread of the transformation undergone by archaic categories in Greece related to the perception of the invisible or the absent presence, that as a result of the incoming of the institutions belonging to the 
polis, as well as the representation technologies which were associated to the emergence of a nouvelle publicity frame. From that threshold it is sought here to situate the idea of a mimetic reason, whose relationship with the truth is founded on a consciousness form enabled by work done by the powers of the imagination and representation.

Keywords: mimesis; representation; eidolon; eikon; image; mimetic reason.

\section{PublicidAD Y DIÁlOGO}

Deseo comenzar estas líneas resaltando aquello que en la propia palabra "diá-logo" nos señala el prefijo, a saber, algo así como una escisión del logos, pues, de inicio, esta partición puede ser concebida como indicio del desgajamiento de Alétheia, es decir, del ámbito complejo en el que, mediante el ejercicio de la palabra poética, se hallaban profundamente imbricados Memoria, Verdad y Justicia. Se trata de un resquebrajamiento que, como lo mostrara magistralmente Marcel Detienne (2004), en su clásico libro Los maestros de verdad en la Grecia arcaica, adviene menos por usura o por alguna teleología interna que por la irrupción de nuevas configuraciones y prácticas sociales, así como de nuevas tecnologías de la palabra que les están asociadas. Detienne (2004) cifra el inicio de esta mutación del espacio social y simbólico de la Grecia antigua en la incorporación de gente del común a la casta guerrera, a raíz de la transformación de los métodos de combate que implicaron las formaciones hoplitas, lo cual equivale a decir que la necesidad de reconfigurar los ejércitos mediante el alistamiento de una infantería de extracción popular habría desatado un proceso de democratización que, más tarde, desembocó en la isonomía plena de los ciudadanos:

La clase guerrera, grupo social cerrado en sí mismo, desemboca, en el devenir de la sociedad griega, en la institución más nueva, más decisiva: la ciudad, como sistema de instituciones y como arquitectura espiritual. En el medio de los guerreros profesionales se esbozan determinadas concepciones esenciales del primer pensamiento político de los griegos: el ideal de Isonomía, representación de un 
espacio centrado y simétrico, distinción entre intereses personales e intereses colectivos (p. 153).

Así, es en el seno de la casta guerrera donde Detienne identifica las primeras manifestaciones de una palabra deliberativa y profana, o sea, firmemente anclada en el presente de la decisión acerca de lo común, palabra diálogo, intercambiable, cuyo estatuto prefigura el de la palabra jurídica de los tribunales, pero también el de la palabra filosófica, en la medida en que en ambos casos lo que se busca es la demostración, es decir, la fuerza que proviene del asentimiento social. Esta palabra, pública y horizontal, se opone a la palabra sagrada del aedo y del Rey de Justicia, cuyo principal atributo es la eficacia o, lo que es lo mismo, la capacidad de manifestar "lo que fue, lo que es, lo que será”, y a la que se concebía como una realidad natural, física, en tanto que es fecunda o estéril, pero se arraiga verticalmente en lo inmemorial para actualizarlo, para hacer visible lo invisible; y en esa medida, no puede ser ni lejanamente la expresión de la voluntad ni de la agencia humanas. Palabra-diálogo secularizada, que se inscribe en el tiempo de los hombres y es complemento indispensable de la acción humana y que tiene por objeto principal los asuntos del grupo, "los que interesan a cada uno en su relación con los demás":

Instrumento de diálogo, este tipo de palabra no obtiene ya su eficacia de la puesta en juego de fuerzas religiosas que trascienden a los hombres. Se funda esencialmente en el acuerdo del grupo social que se manifiesta mediante la aprobación y la desaprobación. Será en las asambleas militares donde, por primera vez, la participación del grupo militar funde el valor de una palabra. Será allí donde se prepare el futuro estatuto de la palabra jurídica o de la palabra filosófica, de la palabra que se somete a la "publicidad" y que obtiene su fuerza del asentimiento de un grupo social (Detienne, 2004, pp. 151-152).

Pero lo que para el pensamiento deliberativo y filosófico terminó por constituir un campo de oposiciones contradictorias, para la palabra arcaica no era sino el abigarrado campo de la complemen- 
tariedad de los contrarios: pensamiento ambiguo para el cual las potencias de la memoria se complementaban con las del olvido, es decir, un ámbito en el que la polaridad entre Alétheia y Lethé describía una zona intermedia, de deslizamientos recíprocos, en la que la negatividad no quedaba aislada, excluida del Ser, sino más bien constituía "un pliegue de la 'Verdad', su sombra inseparable", ya que en ese horizonte las "dos potencias antitéticas no son [...] contradictorias, [sino que] tienden la una hacia la otra; lo positivo tiende hacia lo negativo, que, en cierto modo, le 'niega', aunque no puede sostenerse sin él” (Detienne, 2004, pp. 126-127). En la palabra de las musas, "abigarrado tejido donde se entrelazan armoniosamente los contrarios" (p. 121), concurren, en efecto, potencias como Peithô, con su poder de seducción a través de la palabra, o como Apaté, cuyo poder radica en entreverar la Verdad con el Engaño (Pseudés) mediante la confusión de las apariencias: hacer creíble lo increíble, manifiestar el carácter enigmático de la verdad y el sentido oculto de las palabras; y en suma, expresar tanto "la ambigüedad del engaño como el engaño de la ambigüedad" (p. 131). No sorprende, entonces, que, una vez que haya logrado objetivar a la palabra, al logos, el pensamiento racional cifre su reflexión -y su sospecha- en esa capacidad de seducción y engaño, como lo dejan ver los testimonios de la retórica y de la sofística y, por supuesto, del propio Platón.

\section{EIDOLON, EIKON}

El ámbito de incidencia privilegiado de Apaté son los fenómenos de aparición, como los que se producen en el sueño, o por obra de un dios, o bien cuando, por un instante, se hace visible el fantasma -la psyché o sombra- de un difunto, es decir, fenómenos asociados con la noción arcaica de eidolon, presencia real de una imagen que, sin embargo, está atravesada por una lejanía que la vuelve inasible y la impregna de ausencia; dialéctica de la presencia y la ausencia, que traduce la irrupción de lo invisible dentro de lo visible y que talla profundamente las marcas de la alteridad radical en el mundo de los humanos. Pero si en el pensamiento arcaico la semejanza del eidolon con el objeto familiar implicaba una suerte de copertenencia 
o de participación en un mismo orden ambiguo de realidad, en el horizonte de la racionalidad demostrativa lo que se esboza es más bien una teoría de la semejanza, que a su vez conducirá, más tarde, a la elaboración de una teoría general de la mimesis.

Será Platón quien inserte esta dialéctica dentro de un registro reflexivo que le habría de imprimir un signo claramente inverso, pues, como sabemos, para él la imagen deja de inscribir la huella de lo Otro en lo Mismo y se convierte, más bien, en un derivado segundo, en una copia. La imagen ya no es una aparición, sino un mero "parecer": algo visible, cuyo estatuto perceptivo será definido en términos ontológicos, en función de la unidad de un Ser carente de pliegues y de sombras. Esta teoría de la semejanza inscribe lo ficticio y lo ilusorio en el espacio definido por la división tajante entre el ser y el no-ser, entre lo verdadero y lo falso. Como lo explica Jean-Pierre Vernant (1975), en tanto "ser de semejanza, la imagen es del orden del parecer, del phainen: ella se hace ver, como apariencia de aquello que (ella [misma]) no es". En ese sentido, la imagen es también apariencia falsa, pues de "la cosa que imita la imagen no manifiesta más que su aspecto exterior, la forma concreta, lo que perciben los sentidos desde tal o cual ángulo" ( $\mathrm{p}$. 10). Pero la inversión platónica no es en realidad sino el corolario de un proceso de cambio gradual en el estatuto de la imagen, que podemos describir como el paso del eidolon al eikon.

Para Suzanne Saï, la distinción que el propio Platón estableciera entre esas dos nociones, así como la larga historia de conceptualizaciones de la imagen que de ella deriva, tienen su origen en la etimología misma de esos términos, pues, según esta autora, a pesar de que ambos comparten la raíz wei- -asociada con el acto de ver, que también comparten, por ejemplo, con eidos e idea-, eidolon pertenece exclusivamente a la esfera de lo visible, mientras que eikon indica más bien una relación de adecuación o conveniencia. De esta manera, la oposición entre estos dos términos daría cuenta de una división, por así decir, congénita, conforme a la cual el eidolon sería claramente una forma de simulacro o facsímil, mientras que el eikon sería más bien una forma simbólica: 
La imagen/eidolon está dirigida exclusivamente a la mirada [...]. Por el contrario, la imagen/ eikon depende siempre de una comparación. Desde Aristófanes, se atestigua la aparición de eikon en el sentido técnico de una "imagen retórica". A partir de Aristóteles, quien hace del eikon una forma particular de metaphora, la palabra aparecerá regularmente, junto con parabolè y paradeigma, en el listado de figuras que elaboran los rétores. [...]. Efectivamente, [el eikon] se dirige esencialmente a la inteligencia, de la cual necesita para ser percibido en cuanto tal. Si bien es suficiente con tener ojos para dejarse seducir por un eidolon que reproduce la apariencia de su modelo, se requiere capacidad de razonar para poder aislar el carácter genérico presente en el eikon y en su modelo y reconocer la imagen en cuanto tal (Saïd, 1987, p. 323). ${ }^{1}$

Para esta autora, la distinción radica en el hecho de que, a diferencia del eidolon, que pretendería suplantar, gracias a su mero carácter sensible, a su original, el eikon remite al mismo, mediante la señalización de rasgos característicos que, aunque hacen posible su reconocimiento sensible, quedan subordinados a una aprehensión estructural, que debe involucrar múltiples niveles y que implica una operación comparativa, de tipo más bien intelectual. Es con base en esta dicotomía de origen que Platón habría logrado invertir los registros y sustraer términos como eidos e idea del dominio de lo visible, para reservarlos a esa "visión espiritual" que se produce con los "ojos del alma", englobando bajo la noción de eidolon todas aquellas realidades, derivadas y secundarias, de lo que se presenta como aquello que no es, ya sea que se trate de falsas virtudes, falsos placeres o falsas

1 “'L'image/eidolon s'adresse au regard et au regard lui seul [...]. Au contraire l'image/ eikon repose toujours sur une comparaison. Dès Aristophane, eikon est attestée au sens technique d' "image rhétorique". A partir d'Aristote qui fait de l'eikon une forme particulière de metaphora, le mot figurera régulièrement, aux côtés de parabolè et de paradeigma, dans la liste des figures que dresseront les rhéteurs [...]. De fait, elle s'adresse essentiellement à l'intelligence. Elle a en effet besoin d'elle pour être perçue comme telle. S'il suffit d'avoir des yeux pour se laisser séduire par un eidolon qui reproduit l'apparence de son modèle, il faut être capable de raisonner pour isoler le caractère générique présent dans l'eikeon et dans son modèle et reconnaitre l'image comme telle." Las traducciones de los textos editados en otro idioma, que aquí se refieran, son mías. 
ciencias y técnicas -como lo será, para él, la retórica. Más aún, sería esa dimensión "intelectual” o de adecuación inherente al eikon la que habría permitido a Platón concebir una especie particular de imagen o eikon filosófico, que, al igual que los mitos, resulta un instrumento válido de conocimiento, en tanto que permite la figuración de lo invisible, pero a la manera de un vehículo propicio para la aprehensión sensible de las esencias, pues, a pesar de que Platón invierte el signo de la psyché -que designaba el espectro intangible de quienes no aparecen entre los vivos más que como sombra y fantasmagoría-, haciéndola pasar de lado del ser; y de que, inversamente, hace a los eidola designar a los cadáveres así como a las almas que todavía tienen rastros de corporeidad (Saïd, 1987, p. 316), para él la imagen se ubica en un plano ontológico, no psicológico:

La imagen en sentido ontológico es para [Platón] una noción de la mayor importancia y se convierte en un concepto elaborado. Y es que todo en el mundo es imagen: tanto los seres de la naturaleza, creación de Dios, como los objetos fabricados por el hombre, son las imágenes de las Ideas; y unos y otros tienen su imagen en las reproducciones que de ellos hacen los artistas. La imagen está asociada a todo pensamiento, a toda actividad: imágenes, las representaciones de la memoria y del sueño, del temor y la esperanza; imagen, el material de la actividad del conocimiento, ya sea que el filósofo se esfuerce por representar la noción de lugar o para formular en su pensamiento las imágenes de las Ideas; por último, es en la imagen que reposa a actividad creativa tanto del hombre como de Dios. También puede decirse de la imaginación, concebida como el acto de producir imágenes, que se trata de una actividad "artesanal" más que psicológica: su forma suprema es la del demiurgo que crea el mundo teniendo las Ideas como modelo y su forma inferior la del artista o el sofista, triplemente degradada (Armisen-Marchetti, 1979, p. 26). ${ }^{2}$

2 "L'image au sens ontologique est pour lui une notion de première importance et devient un concept élaboré. Cest que tout dans le monde est image: les êtres de la nature, création de Dieu, comme les objets fabriqués par l'homme, sont les images des Idées; ils ont eux-mêmes pour images les reproductions qu'en font les artistes. L'image est associée à tout pensée, à toute activité: images, 
Aquí se puede ver cómo esta ontologización no sólo convierte a la imagen icónica en vehículo de la creación demiúrgica, sino que, además, instaura durablemente la dualidad que más tarde habrá de oponer antagónicamente al ídolo -en tanto imagen falsa- y al ícono -en tanto imagen divina. La enorme importancia que esta dimensión "creativa" e "intelectual" - o de adecuación estructuraldel eikon cobrará dentro de la formulación de la teoría general de la mimesis -y por supuesto de la poética- no debe obstar para que sean desatendidos los reparos que hace Vernant a las tesis de Saïd, en la medida en que en ellos se cifra la posibilidad de revertir la pérdida de sentido histórico que resulta de la proyección al periodo arcaico de categorías que en realidad se desarrollaron durante la época clásica y su posteridad.

\section{LA ARQUEOLOGÍA DE LA IMAGEN}

En efecto, lo que Vernant reprocha a Suzanne Saïd es un error de perspectiva, conforme al cual la dualidad eidolon/ eikon, tan clara en el contexto de la relación histórica del cristianismo con las imágenes, ${ }^{3}$ sólo puede apreciarse en el periodo arcaico si se proyecta sobre él una categorización de la imagen que no aparece en las fuentes anteriores al siglo $\mathrm{V}$, es decir, antes de que hubiera iniciado la formulación de una teoría general de la mimesis bajo el impulso de la escuela eleática, pues, para Vernant, no es sino en el contexto de la conformación de una conciencia mimética que el doble se convertirá en apariencia o, lo que es lo mismo, que la imagen podrá

les représentations de la mémoire et du rêve, de la crainte et de l'espoir ; image, le matériau de l'activité de connaissance, que le philosophe fasse effort représenter la notion de lieu, pour former dans sa pensée les images des Idées; enfin, c'est sur l'image encore que repose l'activité créatrice de l'homme comme de Dieu. Aussi peut-on on dire de l'imagination, conçue comme l'acte de produire des images, qu'elle est une activité "artisanale" plus que psychologique; sa forme suprême est celle du démiurge qui crée le monde en prenant les Idées pour modèle; sa forme inférieure, celle de l'artiste et du sophiste, triplement dégradée."

${ }^{3}$ Como lo expresa Suzanne Saïd (1987, p. 328), es en razón de esa dualidad que los traductores de la Septuaginta apelarán al término eikon para traducir el famoso pasaje de Génesis 1:26, que muestra a Dios creando al hombre "a su imagen y semejanza", es decir, en tanto ícono fiel. 
adquirir sus atributos genuinamente icónicos -es decir, artísticos, creativos, intelectuales y representativos:

En ese sentido, S. Saïd no toma en cuenta en su estudio el hecho mayor de que los términos del par eidolon/ eikon no son contemporáneos. Eikon no se utiliza antes del siglo V. Esa innovación parece tanto más significativa cuanto que se produce al mismo tiempo que hace su aparición en el vocabulario otro grupo destinado a expresar valores de simulación e imitación: mimos, mimema, mimeisthai, mimesis, términos que se aplican a las figuras plásticas, a la poesía y a la música, pero que están especialmente vinculados con la instauración de un nuevo tipo de obra literaria, el espectáculo dramático, cuya originalidad consiste en traer a la presencia, para que sean vistos por el público directamente en el escenario, a los personajes "ficticios" que la epopeya relataba en sus narraciones en estilo indirecto. Eikon, mimeisthai, tragedia: la simultaneidad de estos tres órdenes de hechos resulta tanto menos fortuita que, siendo Platón el primer filósofo que elabora una teoría general de la imagen en tanto imitación de la apariencia, el espectáculo trágico constituye, según él, el prototipo por excelencia de las técnicas ilusionistas que pone en obra la mimesis (Vernant, 1990, p. 231). ${ }^{4}$

Este diferendo no resulta nada sorpresivo, si se tiene en cuenta la importancia que tiene dentro del proyecto de Vernant (1996) la reconstrucción de ese proceso histórico que lleva del eidolon al

4 "A cet égard, S. Saïd ne prend pas en compte, dans son étude, ce fait majeur: dans le couple eidolôn/eikon les deux termes ne sont pas contemporains. Eikon n'est pas en usage avant le Vème siècle. Cette innovation semble d'autant plus significative qu'elle se produit en même temps que fait son apparition une autre tranche de vocabulaire, pour exprimer les valeurs de simulation et d'imitation: mimos, mimema, mimesithai, mimesis - termes qui s'appliquent aux figures plastiques, à la poésie et à la musique, mais qui sont spécialement liés à l'instauration d'un nouveau type d'œuvre littéraire, le spectacle dramatique, dont l'originalité consiste à rendre présents aux yeux du publique, pour qu'ils les voie directement sur la scène, les personnages et les événements «fictifs» que l'épopée relatait sous forme de récit, en style indirect. Eikon, mimeisthai, tragédie -la simultanéité de ces trois ordres de faits paraîtra d'autant moins fortuite que si Platon est le premier philosophe à élaborer une théorie générale de l'image comme imitation de l'apparence, le spectacle tragique constitue, selon lui, le prototype para excellence de ces techniques illusionnistes mises en œuvre par la mimesis." 
eikon y que ilustra con claridad el título de un estudio fundamental, "Del doble a la imagen", en donde este autor describe cómo, de las múltiples expresiones que designaban al "ídolo divino", en su variedad de usos, aspectos y formas materiales, sólo eikon y mimema, que corresponden a los términos mediante los cuales se nombraba a la gran estatua cultual, establecerán una relación cada vez más definida con las ideas de semejanza, imitación o representación figurativa en sentido estricto. Concretamente, explica Vernant, es en el umbral de los siglos v y IV, gracias a la elaboración de una teoría de la mimesis y la imitación por parte de Jenofonte y Platón, que llega a consumarse "el proceso que lleva de la presentificación de lo invisible a la imitación de la apariencia" y que pueden despejarse los rasgos específicos de la categoría de representación figurativa. En ese umbral ocurre un hecho:

El símbolo a través del cual una potencia del más allá, es decir, un ser fundamentalmente invisible, es actualizado y presentificado en este mundo, se transformó en una imagen producida por una imitación experta, que en razón de su carácter técnico y docto, de procedimiento ilusionista, entra a partir de entonces en la categoría general de lo "ficticio" - eso que nosotros llamamos arte. Desde entonces la imagen pertenecerá al ilusionismo figurativo, en la medida en que se la separe del ámbito de las realidades religiosas (Vernant, 1996, pp. 340-341). ${ }^{5}$

Vernant (1990) demuestra arqueológicamente que el proceso conducente a la conceptualización de la imagen en tanto artefacto ficticio estuvo asociado tanto con la necesidad experimentada por los antiguos griegos de "reproducir en una materia inerte, mediante artificios técnicos, el aspecto visible de aquello que, en vida, de

5 'Le symbole à travers lequel une puissance de l'au-delà, c'est-à-dire un être fondamentalement invisible, est actualisé, présentifié dans ce monde-ci, s'est transformé en une image, produit d'une imitation experte qui, par son caractère de technique savante et de procédure illusionniste, entre désormais dans la catégorie générale du «fictif» - ce que nous appelons l'art. Dès lors l'image relève de l'illusionnisme figuratif autant et plus qu'elle ne s'apparente au domaine des réalités religieuses." 
entrada manifiesta ante la vista su valor de belleza -de belleza divina-, en tanto que thauma idesthai, maravilla visible" (p. 226), ${ }^{6}$ como con el vuelco histórico que representó el advenimiento de la gran estatua cultual en el marco del templo.

No es casual, en efecto, que el ámbito de discusión en el que se elaboró la teoría general de la mimesis fuera en buena medida el referente a la figuración de la divinidad y a las formas de semejan$\mathrm{za} /$ diferencia de lo humano en relación con ella, pues el progreso técnico de las "artes figurativas" estuvo acicateado por la necesidad de traducir plásticamente, en la materia inerte, el asombro que provocaba la charis, el esplendor de una juventud inalterable de la que sólo gozan los dioses inmortales, y que aparecía en los hombres como un "reflejo divino". De manera que, en realidad, no es que la estatuaria buscara figurar a los dioses a semejanza de los humanos, sino que, inversamente, para los griegos antiguos era el cuerpo humano el que, mientras gozaba del brillo de su juventud, era espejo de la divinidad. Y es al deseo de reproducir esa belleza divina que se debe el avance en la representación plástica de la figura humana.

Pero paralelamente a ese perfeccionamiento técnico, tuvo lugar un proceso más profundo y fundamental, relacionado con el cambio de sentido en los usos de la imagen, pues la estatua cultual surge cuando el favor divino del ídolo -objeto eficaz y, por lo mismo, celosamente resguardado dentro del ámbito ritual- deja de estar reservado a un grupo cerrado y se inserta dentro de una institución propia de la era de la ciudad, es decir, cuando se convierte en objeto de un culto público:

$\mathrm{Al}$ igual que el templo, la imagen reviste un carácter de publicidad plena. Podría decirse de la estatua que, en adelante, todo su "esse" consiste en un "percipi", su ser en un "ser percibido". Ya no posee otra realidad más que su apariencia, ninguna otra función ritual más que ser vista. Alojada en el templo en el que hace residir al dios, no

6 "l'effort entrepris par les anciens Grecs pour reproduire, dans une matière inerte, grâce à des artifices techniques, l'aspect visible de ce qui, vivant, manifeste d'emblée au regard sa valeur de beauté-de divine beauté- en tant que thauma idesthai, merveille à voir." 
se la pasea más. Expresiva por su forma, no tiene más necesidad de ser vestida, llevada en procesión, bañada... No se le exige más operar como una fuerza eficaz, sino actuar sobre la mirada del espectador, traducir para él de manera visible la presencia invisible del dios y comunicarle alguna enseñanza sobre la divinidad. La estatua será así representación en un sentido auténticamente novedoso (Vernant, 1996, p. 347). ${ }^{7}$

Fue entonces en el marco novedoso del uso público de la imagen divina en el que la figura humana terminó por desprenderse de los valores religiosos con los que originariamente estuvo asociada y pudo asumirse como figuración plena e incluso monumental de sí misma; y es también en ese contexto en donde, correlativamente, la imagen perdió finalmente su estatuto de encarnación de lo invisible para devenir plenamente una imitación de la apariencia, convirtiéndose así en un fenómeno propicio para la reflexión acerca de la semejanza y los poderes del imaginario y de la representación.

\section{EL ESPACIO GRÁFICO}

No debiera sorprender, entonces, que para Simónides de Ceos, quien, como se sabe, afirmaba que la pintura es una poesía silenciosa, la palabra resulte ser ni más ni menos que una imagen, es decir, un eikon, pues, como señala Neus Galí, lo que buscaba este poeta -al que se atribuye la invención de la mnemotecnia, es decir, el haber transformado la palabra de la musa en una tekhné susceptible de remuneración- era conferir a su obra el rango monumental de las artes figurativas, en adecuación a un contexto en el que tanto los aristócratas como los tiranos o los ciudadanos adinerados

${ }^{7}$ "Comme le temple, l'image revêt un caractère de pleine publicité. On pourrait dire de la statue que, désormais, tout son «esse»» consiste dans un «perci$p i$ i), tout son «être» dans un «être perçu». Elle n'a plus d'autre réalité que son apparence, plus d'autre fonction rituelle que d'être vue. Logée dans le temple, où elle fait résider le dieu, on ne la promène plus. Expressive par sa forme, elle n’a plus besoin d'être habillée, processionnée, baignée... On ne lui demande plus d'opérer dans le monde comme une force efficace, mais d'agir sur les yeux du spectateur, de traduire pour lui de façon visible la présence invisible du dieu et de lui communiquer un enseignement sur la divinité. La statue est «représentation» en un sens vraiment nouveau." 
deseaban dejar constancia de su poder y memoria de su paso y, para ello, encargaban monumentos suntuarios. "Y el término monumento, en su sentido más amplio -y etimológico: 'aquello que perpetúa el recuerdo'-, es particularmente adecuado para referirse a los poemas conmemorativos" (Galí, 1999, p. 164), por lo cual parece legítimo concluir que fue su inserción en la esfera de lo público la que arrastró hacia el ámbito de la imagen icónica, por vías paralelas, tanto al ídolo como a la poesía arcaicos. Ahora bien, como ya se habrá intuido, un elemento fundamental dentro de la conformación del campo de la figuración gráfica-agrupada en el término graphein-, es esa nueva tecnología de la palabra que constituyó la escritura alfabética. Al respecto, Marcel Detienne (2004) escribe:

La invención de la mnemotecnia responde a la misma intención que otro perfeccionamiento técnico atribuido a Simónides: la invención de las letras del alfabeto que permitirían una mejor notación escrita. Cabe destacar, en efecto, que los poetas líricos recurren a la escritura, y no ya a la sola recitación, para hacer conocer sus obras. Desde el siglo VII, la escritura es la forma necesaria de publicación: ha dejado de estar, como en el mundo micénico, unida a estructuras económico-sociales de acumulación; ya no apunta esencialmente a consolidar el poder de los que dirigen: [ahora] es un instrumento de publicidad (p. 171).

Por supuesto, en este punto resulta inevitable pensar también en las implicaciones que tuvo el tránsito de la Justicia, de la Diké, del ámbito de la oralidad y el ritual, al de la publicación de la ley mediante su inscripción gráfica en el espacio de la ciudad. En su estudio sobre la antropología de la lectura en Grecia antigua, Jesper Svenbro (1993) documenta filológicamente el vínculo que llegó a existir entre el término nómos y la lectura y atribuye a esta última un lugar primordial dentro de la ciudad griega, en la medida en la que la actividad de los magistrados, por cuya boca se regulaba el comportamiento del cuerpo cívico, consistía en una "exégesis", en una "exposición oral" que, en realidad, no era sino una lectura en voz alta: 
La noción de una "propagación oral", que es el sentido fundamental de nómos, corresponde al sentido de "expositor oral" que implica exegetes. El exegetes [o exégeta], en el sentido de un "lector", complementa al nómos, en el sentido de una "lectura". Esta profunda complementariedad, que no tiene nada de gratuita, es sintomática de la manera en la que la cultura griega desarrolló una concepción de la ley como algo inseparable de su concepción de la lectura, y de cómo entre ambas se confería el más alto valor a la lectura en voz alta (p. 122). ${ }^{8}$

Ciertamente, como lo señalara en su momento Eric Havelock, y tras él la propia Neus Galí, la escritura alfabética no sólo fue indispensable para que, gracias a la sustracción del lenguaje que ella opera respecto a la corriente secuencial y rítmica del habla, la palabra fuese percibida como algo separado del flujo del discurso y, por ende, concebida como imagen, sino que además, de manera concomitante, la escritura resultó fundamental para que la tradición, dentro de la cual operaba la "Enciclopedia cultural" que regía el comportamiento del cuerpo cívico, entrara en el espacio gráfico en el que se habría de extrañar respecto de sí y convertirse en crítica:

Si es cierto que Simónides estuvo entre aquellos que se ocuparon de organizar los textos canónicos de Homero, esta actividad le habría puesto en una relación especial, "literaria", con la epopeya, habitualmente recitada y escuchada, no escrita ni leída. [...]. La escritura hace posible que la epopeya salga de la memoria viviente de los hombres. La convierte en texto y, por consiguiente, en algo manipulable, susceptible de ser sometido a operaciones de revisión, crítica, corrección, reorganización, interpolación, eliminación, etc. Al mismo tiempo, con el establecimiento de un texto homérico definitivo aparece la idea de un "original", un referente escrito res-

8 'The notion of an 'oral distribution,' which is the fundamental meaning of nómos, corresponds to that of the 'oral distributor' that is implied in exegetes. The exegetes, in the sense of a 'reader', complements the nómos, in the sense of 'reading.' That profound complementarity, which is anything but gratuitous, is symptomatic of the way in which Greek culture developed a conception of law inseparable from its conception of reading, both of which set the very highest value upon the word spoken aloud." 
pecto del cual toda variante se entenderá como desviación. Es precisamente esa idea de original que surge con la escritura la premisa básica para el nacimiento no sólo de una literatura, sino de un pensamiento teórico acerca de ella (Galí, 1999, p. 39).

Esta objetivación no sólo concierne a la creación de la "literatura" en tanto palabra icónica, sino también al extrañamiento del lógos respecto a las miríadas de historias y genealogías, que cesarán de vivir y proliferar en la variación de un presente siempre renovado una vez que su pluralidad haya sido capturada por la escritura en las redes textuales de lo único y se las haya convertido en "mito". Detienne considera la empresa de escritura de los relatos genealógicos -los lógoi- que circulaban en Grecia por parte de Hecateo como uno de los momentos culminantes de ese proceso de "invención de la mitología”, pues es mediante su escritura narrativa, en prosa y además firmada en primera persona, que el logógrafo de Mileto considerará explícitamente esa pluralidad de relatos ya no "en la forma de un plural inmanente a una tradición que se vuelve a contar y no deja de producir variantes o de inventar versiones siempre nuevas, sino como una multiplicidad de dichos que de pronto resultan visibles por su juxtaposición en el espacio gráfico que ocupa el contarlos y, al mismo tiempo, el compararlos" (Detienne, 1985, p. 93).

Así, como lo dejan ver los ejemplos de los magistrados o "exégetas", con su lectura en voz alta, o del poeta y el logógrafo, cuando al fijar la VOz no sólo transcriben, sino también hacen crítica de la tradición -e inauguran la tradición de la crítica-, el graphein no es el ámbito cerrado de la pura textualidad, sino un espacio de circulación y dispersión semánticas, en el que adquiere forma el conflicto entre las diferentes formas de la memoria, la legalidad y el conocimiento que coexistían en el espacio de la polis.

\section{LA RAZÓN MIMÉTICA}

Cuando al templo y al monumento se sume esa otra esfera de publicidad que es la escena, habrá quedado de manifiesto el desarrollo pleno de lo que en la estatua cultual sólo se encontraba en germen: la transformación de la imagen en espectáculo, pues, en 
efecto, será en la falla, en el intersticio conflictivo del espacio gráfico anteriormente descrito, donde la imagen-artificio se convierta en un medio para presenciar públicamente una ausencia, conforme a una modalidad particular en la que la palabra, los héroes y los valores del pasado reverberen literariamente, creando esa forma de conciencia mimética que es la conciencia trágica.

Desde este punto de vista, escriben Vernant y Vidal (2002) en Mito y tragedia en Grecia antigua:

puede decirse que la tragedia es la ciudad que se convierte en teatro, que se escenifica a sí misma ante el conjunto de ciudadanos [...].

Cuando están viendo a los héroes trágicos, los espectadores son conscientes de que éstos no están y de que no podrían estar presentes, ya que, vinculados a una época totalmente caduca, pertenecen por definición a un mundo que ya no existe, a un inaccesible más allá. Así, la "presencia" que encarna el actor en el teatro es siempre el signo o la máscara de una ausencia en la realidad cotidiana del público. A la vez que el espectador se entusiasma con la intriga y se conmueve ante lo que ve, no deja de reconocer que se trata de falsas apariencias, de simulaciones ilusorias -en una palabra, de "mimética"-. Así es como la tragedia descubre un nuevo espacio en la cultura griega, el de lo imaginario entendido y sentido como tal, es decir, como una creación humana basada en el puro artificio (pp. 25-27).

No sólo se trata, entonces, de señalar que, como reza el adagio del filólogo alemán Walter Nestle, la tragedia nace cuando se empieza a contemplar al mito con el ojo del ciudadano, sino de recalcar además que, al tener lugar en el espacio gráfico del eikon, ese nacimiento literalmente espectacular instaura lo que me atrevo a denominar una racionalidad mimética, es decir, una reflexión acerca de la escena política -en sentido estricto-y del lugar fundamental que en ella ocupa el imaginario en tanto forma específica de la conciencia. Así, en tanto lugar de la aparición mimética -literaria y escénica- de la presencia ausente, el espacio del imaginario define la forma posible de una conciencia representativa. Como lo manifiesta el reconocido helenista Charles Segal, es posible que la división en dos etapas de la creación de 
una tragedia -texto y performance- haya contribuido en la toma de distancia respecto a los asuntos del mito, que implica el crítico, abierto y conflictivo espíritu de la tragedia, el cual, en lugar de la celebración unilateral -monumental, podríamos decir- del héroe, a la que tendía la lírica coral, combina la participación empática con la presentación de diferentes puntos de vista, actitudes y perspectivas, sin que ninguna de ellas pueda ser considerada necesariamente la última o la más correcta. Especula Segal (1986):

[También es posible] que este modo de producción en dos etapas haya sensibilizado al poeta trágico respecto al doble sistema de comunicación, verbal y visual, que implica su arte: el poder de visualización inherente al poder de fabricar imágenes de la propia palabra y el acto concreto de visualización de la escena teatral. La coexistencia de la representación verbal y la visual que es única del teatro implica, casi en todos los aspectos, dicotomía, contradicción y paradoja en lo relativo a la existencia de la verdad (p. 78). ${ }^{9}$

La elusividad del texto trágico, con su contrapunto perfectamente orquestado entre profundidad y superficie y entre apariencia y realidad, responde a una nueva autoconciencia, propiciada por el espacio gráfico, respecto a lo que acontece detrás y por debajo de lo evidente, esto es, respecto al contenido de verdad, que no puede ser mostrado explícitamente mediante la acción y el lenguaje escénicos. Más tarde, ese complejo y multidimensional espacio, que define el carácter representativo de la mimesis, será racionalizado y epistemológicamente reconvertido, mediante la conceptualización de su vinculación entre diversas modalidades y ámbitos de experiencia, como una técnica de producción intencional de imágenes icónicas, derivada de la facultad humana de establecer semejanzas

9 " [It is also possible] that this two-stage mode of production sensitizes the tragic poet to the two systems of communication and representation, verbal and visual, that this art involves: the power of visualization inherent in the image-making power of the world itself and the concrete act of visualization on the theatrical stage. The coexistence of verbal and visual representation unique to the theater involves at nearly every point, dichotomy, contradiction, or paradox in the existence of truth." 
dentro de esquemas lógicos y causales. ${ }^{10}$ Por mi parte, prefiero seguir al propio Segal (1997), quien, con base en su análisis de Las Bacantes, califica esta dimensión como autoconciencia mimética, metatragedia o poética dionisíaca, pues la mención de Dionisios, el dios de la máscara, no puede ser aquí gratuita, en tanto que, como lo recuerdan Vernant y Vidal (2002), la máscara se distinguía de la estatua antropomorfa de la época clásica por haber conservado su eficacia simbólica, dentro de un marco ritual asociado con las divinidades que tutelaban las zonas liminares en las que la vida diurna, ordenada y razonable, se trenza casi indiscerniblemente con la muerte, el salvajismo y la locura -o, lo que es lo mismo, las zonas donde al ser humano le es dado relacionarse de manera directa con las distintas formas de la alteridad radical:

Lo que crea Dionisio y lo que provoca también la máscara cuando el actor se la pone es la irrupción en plena vía pública y a través de lo que se hace presente, de una dimensión de la existencia extranjera por completo al universo de lo cotidiano.

10 "La potencia que posee en el vocabulario de Aristóteles la terminología de la 'semejanza' tiene una base lógica: la semejanza es un asunto de cualidades o atributos similares, y en cuanto tal, subsiste en las diversas modalidades de la experiencia [...]. [E]n un contexto referente a las imágenes tanto metafóricas como literales, Aristóteles afirma que una imagen (eikon) es aquello que se produce mediante la mimesis, esto es, mediante la elaboración intencional de semejanzas [...]. La 'semejanza' mimeticamente obtenida es entonces tipificada mediante el caso de la representación visual, aunque Aristóteles es claro, tanto en el caso de las artes pictóricas y plásticas como en el del arte poético, respecto al hecho de que la mimesis no necesita involucrar una relación con particulares identificables, y en ese sentido, no necesita tener una función estrictamente referencial". "The force of the terminology of 'like(ness)' in Aristotle's vocabulary has a logical basis: likeness is a matter of similar qualities or attributes, and as such can subsist in diverse modalities of experience [...]. [I]n a context referring to both metaphorical and literal images, Aristotle states that an image $(e i k o n)$ is that which is produced by means of mimesis, that is, by intentional likeness making [...]. Mimetically rendered "likeness" is, then, typified by the case of visual depiction, though Aristotle is just as clear in the case of pictorial and plastic as in that of poetic art that mimesis need not involve a relationship to identifiable particulars and, in that respect, need not have a strictly referential function." (Halliwell, 2002, pp. 156-157). Respecto al carácter estructural de la semejanza aristotélica, ver también Cárdenas Mejía (1996). 
La invención del teatro, del género literario que escenifica lo ficticio como si fuera realidad, no podía darse sino en el contexto del culto de Dionisio, dios de las ilusiones, de la confusión y de la constante interferencia entre la realidad y las apariencias, la verdad y la ficción (p. 44).

Dionisio, el extranjero perenne, confiere al humano la posibilidad de experimentar un extrañamiento radical, que, como lo demuestra la suerte de Penteo, no es el de la razón insensata, cuya negación de la alteridad que la habita resulta en locura, sino el de la sabiduría mimética de quien, risueño como la máscara del dios, acepta la interrogación que le plantean tanto la alteridad radical del mundo como el enigma de su propia ambigüedad.

\section{BiBLIOGRAFÍA}

Armisen-Marchetti, M. (1979). La notion d'imagination chez les anciens I: Les philosophes. Pallas, 26, 11-51.

Cárdenas Mejía, L. G. (1996). La semejanza en Aristóteles. Estudios De Filosofía, 14, 115-128. <https://revistas.udea.edu.co/index. php/estudios_de_filosofia/article/view/338433>.

Detienne, M. (1985). La invención de la mitología. (Trad. de Marco Aurelio Galmarini). Barcelona: Península.

Detienne, M. (2004). Los maestros de verdad en Grecia arcaica. (Trad. de Juan José Herrera). México: Sexto piso.

Galí, N. (1999). Poesía silenciosa, pintura que babla. Barcelona: El acantilado.

Halliwell, S. (2002). The Aesthetics of Mimesis. Ancient Texts and Modern Problems. Princeton: Princeton University Press.

SAÏD, S. (1987). Deux noms de l'image en grec ancien: idole et icône. Comptes rendus des séances de l'Académie des Inscriptions et Belles-Lettres, 131(2), 309-330. <https://www.persee.fr/docAsPDF/crai_0065-0536_1987_num_131_2_14494.pdf>. 
SEgal, C. (1986). Interpreting Greek Tragedy: Myth, Poetry, Text. Ithaca: Cornell University Press.

Segal, C. (1997). Dionysiac Poetics and Euripides' Bacchae. Princeton: Princeton University Press.

Svenbro, J. (1993). Phrasikleia. An Anthropology of Reading in Ancient Greece. Ithaca: Cornell University Press.

Vernant, J. P. (abril-junio, 1975). Image et apparence dans la théorie platonicienne de la mimêsis. Journal de Psychologie normale et pathologique, 2, 133-160. <https://juanfermejia.files.wordpress. com/2011/04/imagen-y-apariencia-vernant.pdf $>$.

Vernant, J. P. (1990). Figuration et image. Metis. Anthropologie des mondes grecs anciens. 5(1-2), 225-238.

Vernant, J. P. (1996). Mythe et pensée chez les Grecs. Paris: La Découverte.

Vernant, J. P. y Vidal Naquet, P. (2002). Mito y tragedia en la Grecia antigua. (Vol 2. Trad. de Ana Iriarte). Barcelona: Paidós. 